\title{
ENGAGING STUDENTS WITH SOME LEARNING PLATFORMS: ENGLISH TEACHERS' PERCEPTION
}

\author{
Lasmi Febrianingrum \\ Institut Agama Islam Negeri Madura \\ lasmi@iainmadura.ac.id \\ Wahab Syakhirul Alim \\ Institut Agama Islam Negeri Madura \\ wahab-alhabsy@iainmadura.ac.id
}

\begin{abstract}
This study aims to describe the perception of English teachers about the use of platforms in engaging students during online learning. The participants of this study consist of junior and senior high school teachers in some schools in Madura. Their perceptions were investigated in terms of three aspects: effects of using this learning platform on their perceived motivation, the perceived usefulness, and the perceived ease of use of platforms. The study was conducted in the descriptive method. The data were collected by using a questionnaire and selfstructured online interviews. The findings indicated that the teachers perceived that google classroom as the most used LMS and WhatsApp as the most preferred social media since both are user friendly and easy to use. Furthermore, Microsoft PowerPoint or Word and YouTube are the most preferred platform since they are motivating, useful and engaging during English online learning. It was found out that the English teachers are satisfied with the features of the use of these outstanding platforms in their online learning since they provide suitable features for their materials. Moreover, it was found that some teachers choose those platforms since they are more familiar for them to use. Besides, they had been introduced, acquired knowledge and practices on how to use the platform for supporting the learning process. Consequently, it should be training for the teacher about other outstanding learning platforms to be acknowledged and employed in their teaching and learning process.
\end{abstract}

Keywords: English, teachers' perception, learning platform

\section{A. INTRODUCTION}

he outbreak of COVID-19 made some aspects of the world become paralyzed,
including schools. The process of teaching and learning must be done online. This
condition makes some schools make any mass improvement and movement since it forced them to be literate in technology. Nowadays, giving and accepting the materials is in the classroom taught by the teacher and an online class. Since Pandemic COVID-19 came, many people, including teachers and students, must work from home (WFH) and study from home (SFH); thus, most teaching and learning activities were done through the Internet. The Internet offers a broad spectrum of content that is easily accessible to teachers and students' fingertips (Joshi \& Kaur, 2011). It provides many learning platforms with various and compatible features with the process of teaching and learning needs.

Those platforms provided on the Internet would make the teachers try hard to adapt and explore more. In line with Yanti, Setiawan, Nurhabibah, \& Yannuar (2018), they stated that 
teachers should play the main role in adopting and integrating technology in the teachinglearning process. Furthermore, having familiar with some online platforms would give them more references to varying their teaching methodology. However, it also makes the teacher getting frustrated in such limited time to try on and practice the platforms while they also do teaching activities at the same time. Consequently, the terms synchronous and asynchronous mode emerge in online learning, especially during Pandemic Covid-19. Many applications and platforms are provided and can be applied, whether synchronous or asynchronous (Feldman \& Zucker, 2002). Those modes would let the teachers choose their strategies to deliver the materials during the teaching and learning process.

Regarding the consideration and challenge of using online learning platforms, the teachers would adopt the teaching methodology from face-to-face to online. For this reason, it makes not only the students getting shocked but also the teachers themselves. The teacher should think and consider how they conduct the online platforms and think about how to make their students learn about the material and how they understand the materials using online since the teacher cannot see the students' facial expressions whether they understand or not. Moreover, it makes the teacher think about the students' output after having an online class. It deals with the assessment phase. From this case, there is anxiety from the teachers dealing with the teaching and learning process. Many teachers have done several activities with several platforms to make the students engage in the class. The existence of some activities using some online platforms would make students more stay focused on online learning. The activities in the learning process that are integrated with technology, such as an online platform, should be comfortable, fun, and interesting (Muthi'ah \& Galib, 2020). Therefore, this study focuses on what kind of online platforms make students more engaged in the online class and how they perceive dealing with some online platforms they have employed.

\section{B. REVIEW OF LITERATURE}

\section{Synchronous dan Asynchronous Learning}

Synchronous and Asynchronous learning emerged several years ago. However, these terms rise since the outbreak of Covid-19. Face to face teaching and learning activities has to switch to online learning. Online learning can be constructed in various ways, such as using self-paced autonomous study units, asynchronous settings, or synchronous settings (Ryan, 2001). Related to approaches to online learning, Feldman \& Zucker (2002) determine types of approaches in learning-based online known as learning of synchronous and learning of asynchronous. Synchronous learning refers to a learning event in which a group of 
participants is engaged in learning simultaneously. Learning of synchronous is defined as the doctrine with the combination in real situations and conditions through the Internet. Its characteristics contain devices like the direct message, shared whiteboard, connecting audio and video data, the media for distributing, and looking up online presentations. It can be done online via live webinars, instant messaging, and virtual classrooms. Besides, synchronous learning is collaborative and feedback friendly. In this case, there are immediate personal engagement between students and instructors, more responsive exchanges between students and teachers since discussion and sharing ideas can be done asynchronously.

Consequently, it may lessen miscommunications or misunderstandings, lead to greater feelings of community, lessen feelings of isolation, and learners' questions can be answered instantly. There are kinds of synchronous learning that can be employed for high bandwidth and immediacy; Video Conference, Audio Conference, and Collaborative documents and Group Chat and messaging are considered low bandwidth. The example learning platforms are ZOOM Meeting, Google Meet, Cisco Webex, Google Hangout, Skype, GoToMeeting, WhatsApp, and Telegram.

Asynchronous learning is defined as the learning process that occurs at separate times. Learners complete courses in their own time regardless of location. The teachers, the learner, and other participants are not engaged in the learning process simultaneously. There is no real-time interaction with other people. Possibly the best-known context of this term is "Personal time management", referring to the set of habits, rules, and recommendations on how to manage one's time effectively and do as much work as possible within the given amount of time (Covey, 1990). Recently, it is well-known as self-paced learning. With selfpaced learning, students can take the time they need and set their schedule instead of working within a structure set for them by the teachers. Therefore, students can pause and replay lectures and search resources to solve the confusion.

Furthermore, they can access to rich learning materials and resources. Besides, asynchronous learning can be completed through online courses, email, blogs, pre-recorded videos, or webinar online discussion boards. Learning experiences are more accessible to different students (inclusivity) since it is more time for deliberation, reflection, and exploration of course material. However, perhaps course material may be misunderstood or misconstrued without accompanying real-time interaction. There are kinds of asynchronous learning that can be employed for high bandwidth; pre-recorded video/audio, asynchronous discussion with video/audio, and low bandwidth readings with text/images, discussion boards with text/images, email. 


\section{Engagement Principles}

Research shows that deep learning can happen when our students are behaviorally, cognitively, affectively, and socially engaged. Egbert (2007) stated that engagement is usually defined as absorption in an activity and implies a motivation to do the activity. Teachers should do any activities to increase students' engagement levels in the language classroom. Philp \& Duchesne (2016) stated that we could engage students in the language classroom when the following 5 Cs are present in the lesson.

Choice. Students should have a sense of control over their learning. When they have the freedom to choose to do or not do the task, they are likely to be more motivated.

Competence. Students are more willing to work harder and more enthusiastically since they know that they have the knowledge, skills, and ability to accomplish the task individually or with peers' support. Having positive self-efficacy can make a big difference in terms of how much or how little effort students will put in. When they know that what they have done will bear fruit, they will do more engaged and motivated to do the task.

Curiosity. Students are, by nature, curious beings. They want to know how things work, how to solve problems, how to solve a mystery, and how to gain new knowledge. In other words, curious students often engage in knowledge-seeking behaviours. When our tasks or lessons spark their curiosity, they will eagerly inquire, explore, analyze, and synthesize information using available resources to satisfy their desire for new knowledge.

Challenge. When the tasks we set in class are challenging (but not too challenging), and the students can complete them successfully, they will feel a sense of achievement. They feel proud of themselves and want to enjoy more emotionally fulfilling experiences in your language class.

Collaboration. Students need to have a sense of relatedness, feel that they can seek help from their peers, and see their peers as friends and not competitors. The literature on cooperative learning shows that students are more willing to explore and share ideas in group settings, put in more effort when completing language tasks, and develop more positive attitudes towards language learning.

Those engagement factors are in line with Egbert \& Shahrokni (2019). Some principles are dealing with the task engagement process.

Authenticity. Materials and processes that are engaging to students are often those that they consider being authentic. Authentic, in this case, means that students perceive that they can 
learn something important or meaningful. The more task components connect to students' lives outside of school, the more likely they are to be seen as authentic.

Interest. Engagement can be supported by tasks that interest students. Knowing the students' characteristics, the teacher can select and adapt any materials, lessons, or tasks related to what students like or are interested in.

Social interaction. The task should be interactive. Although the task is of less interest/authenticity, there should be an opportunity to discuss, collaborate, and problemsolve with peers, experts, teachers, and other interactants to help students become deeply involved. There should be two-way interaction, teacher to students or students to students.

Scaffolding. Students engage when they have help and support that they can use in meaningful ways. The existence of feedback when students received it can make a difference in the task process or outcomes. Further, accessible and comprehensible task support (e.g., handouts, web links, peers) that students can use as they see fit can help them not get lost or stuck and become involved in the task.

Challenge/skills balance. Students need to work just far enough above their current level not to become bored or frustrated; students work in a space that keeps them moving forward. Needs assessments, interviews, book choices, and other evaluations can be useful in understanding students' current levels.

Structure/autonomy. Tasks should provide what students' needs in order to they can choose and work independently. Besides, it encourages the students to move at their own pace within the curriculum and use feedback and other supports to help them stay on track and understand what they have learned.

From both theories above, it can be concluded that the engagement process can be obtained from the tasks or activities that have some factors such as provide challenges, arouse the students' curiosity, make the students' more motivated since the tasks related to their needs and abilities, make them collaborate with peers or even through teachers' feedback.

Considering the engagement principles and online learning platforms that the teachers employed in this outbreak of COVID-19 Pandemics, teachers do not only prepare one learning platform. Various platforms should cover all students' needs and maintain students' engagement and motivation in learning. There is a proverb. One does not fit all. Therefore, the use of various learning platforms will help the engagement process in learning.

\section{Perception}

Related to platforms for engaging students in an online class, there should be intercorrelated with the teachers' skill and knowledge, and attitude about technology. The 
emergence of the COVID-19 Pandemic makes technology important for the educational process, so the teachers should play the main role in adopting and integrating technology in the online teaching-learning process. There are many factors, which are influencing this process and developing from the previous century till today. Teachers' integration of technology into teaching-learning is also influenced by organizational factors, attitudes

towards technology, and other factors. Personal characteristics such as educational level, age, gender, educational experience, experience with the computer for educational purposes, and attitude towards computers can influence the adoption of a technology(Schiler, 2003). Teachers' attitudes and beliefs towards technology become factors that influence integrating technology, especially learning platforms, into teaching. If teachers' attitudes are positive towards the use of educational technology, they can easily provide useful insight into integrating and adopting technology into the teaching and learning process. Research has shown that teachers' attitudes towards technology influence their acceptance of the usefulness of technology and its integration into teaching and learning(Huang \& Liaw, 2005).

\section{METHOD}

This study investigated the online learning platforms that the teachers employed to make their students engaged in an online class and the teachers' perception of dealing with those online platforms. This study employs a case study on English teachers in Madura using questionnaires and online interviews. The use of these methodologies is to gain perceptions of the teachers who participated in the study. The data were obtained from English teachers in Madura from four regencies; Bangkalan, Sampang, Pamekasan, and Sumenep, who have experience using learning platforms during the COVID-19 Pandemic. The author chose the subjects since Madura considered a place with a low-economic condition and 'orange tone' level for the pandemic situation. With that indigenous condition, we can see that there is such a hard effort switching from face to face learning to online learning. Sharing the questionnaire link to some groups of English teachers using social media; WhatsApp, in Madura, 47 teachers have responded to the online questionnaires. The self-structured questionnaire was used to get information related to the most learning platforms that teachers usually used during online teaching and learning to make their students engage while learning. While the use of an online interview with some teachers using purposive sampling was done to get detailed information related to the reason and the perception of the learning platforms used during the COVID-19 Pandemic. 


\section{FINDINGS AND DISCUSSION}

\section{Most Used Learning Platforms}

Gomez Ray (2016) stated that the online learning platform is a way to structure the instruction, which encourages optimal content organization and student interaction. Online learning platforms can reduce teachers' workload and improve the teaching and learning process inside and outside the classroom (As, 2011). Online learning platforms is a learning tool that brings lecturers, students, and parents have access to general resources, communication tools, and information, both inside and outside the classroom.

From the result of questionnaires and online interviews with English teachers in Madura, online learning platforms vary across them. As seen in the figure below, many teachers are familiar with learning platforms. It can be LMS (Learning Management System) such as google classroom, Edmodo, Schoology, Moodle, e-learning, and interactive learning platforms like centimetre, Kahoot, Quiziz, Padlet, google slides/doc.

In addition, the existence of a learning management system (LMS), social media, and other learning platforms may be interconnected. Therefore, the teacher and students do both asynchronous and synchronous modes of teaching and learning.

\section{Interactive Learning Platform}

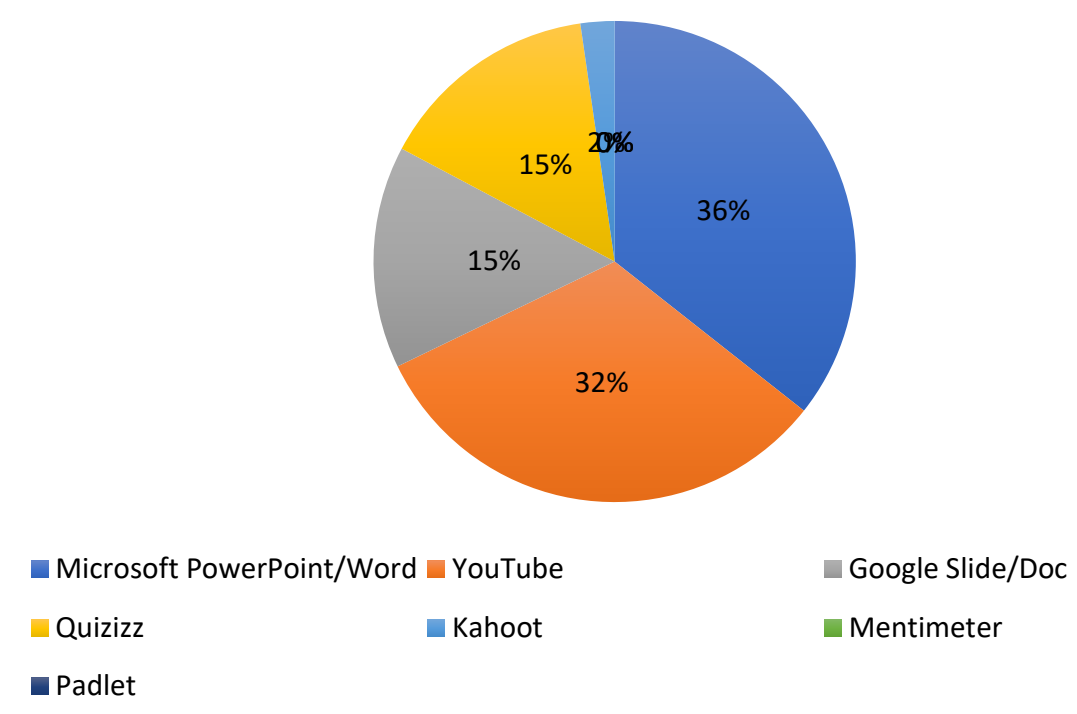

Figure 1. Interactive Learning Platform

The interactive learning platform's most used questionnaire is Microsoft Word/PowerPoint from questionnaire. It can be seen from Figure 1, 36\% of respondents 
chose Microsoft Word/PowerPoint. The second learning platform they have already performed is YouTube that is $32 \%$ of respondents. For the third is $15 \%$ of respondents chose Quizizz and Mentimeter.

From the result, it can be seen that the options of seven learning platforms provided in the questionnaire such as; Microsoft PowerPoint/Word, YouTube, Kahoot, Mentimeter, Google Slide/Doc, Quizizz, and Padlet, they put other platforms such as Google Classroom, WhatsApp, Google Meet, E-learning madrasah, Moodle, Google Form and Zoom as interactive learning platforms. It means that teachers performed more than one application or learning platform to engage in class. It shows that the teachers are very creative and can be considered technological literate, which is in line with (Garmire \& Pearson, 2006) that stated anyone who knows how to create technology, work with it, and benefit from using a technology called technological literacy. It is supported by the findings from the online interview of two teachers that are willing to be interviewed. They mentioned that learning platforms during online classes would encourage students to have deep learning and get more understanding of the lesson. Besides, the students also would be encouraged to have more interaction among the teachers and students. They will not easily be distracted by other activities.

However, the emergence of the above social media, LMS (Learning Management System) as a learning platform mentioned by the teachers from the questionnaire proved that they are already familiar with those technologies although it seems they did not know the appropriate terms for each application whether it was called LMS, social media or application. Furthermore, from the interview, the teachers declared that they used such e-learning or google form since they only have been introduced to those platforms in their schools. Consequently, they are more familiar and be ready to use it.

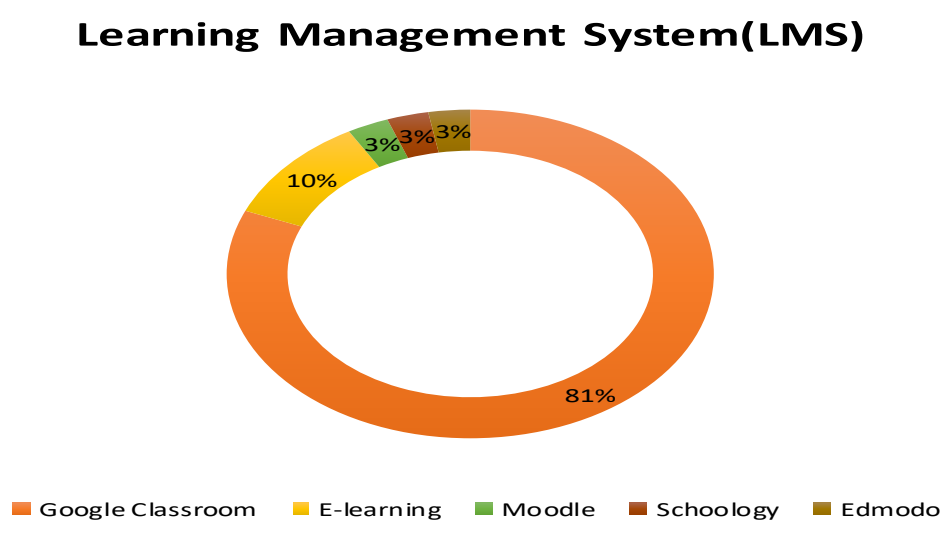

Figure 2. Learning Management System (LMS) 
LMS is a technology that provides a variety of tools to help teachers manage their courses. The use of platforms during the Pandemic is needed to facilitate the teacher in delivering the material to students. Considering the questions in the questionnaire relate to the Learning Management System (LMS) that the teachers employed more is Google Classroom. It can be seen from Pie Chart 2 that about $81 \%$ of teachers of English in Madura used Google Classroom. The second place, $10 \%$, is e-learning Madrasah provided by the Ministry of Religious Affairs. The utilization of google classroom is more familiar for the teachers since they have attended the professional development program in which they acquired knowledge and practices on using Google Classroom at the beginning of the academic year. They attended the workshop that introduced Google Classroom, its benefits, and how to operate it to support the learning process. From that program, teachers obtained a deeper understanding of the application. Hence they were able to maximize its operation. It is in line with Susetyo Harjanto \& Sumarni (2019) showed that teachers use it as a facilitation tool for managing students' tasks, organizing the classroom and accommodating students' interaction.

Those findings show that English teachers in Madura have integrated the Learning Management System (LMS), application, and social media. From an in-depth online interview, they said that one application is not enough. The teachers need Google Classroom to have asynchronous learning, where the students can open the sites anytime and do the task within a certain time. Having this asynchronous platform will help students manage and control their learning and be responsible for the lesson and task. Moreover, WhatsApp and Instagram would be the most selected valuable social media to give more deep interaction between teachers and students in discussing and supervising. Therefore, it will be more intimate and private to explore and facilitate, especially for the students who have less confidence to ask in LMS or other applications.

\section{'Teachers' Perception of Learning Platforms}

Teachers' perceptions were investigated in three aspects: Effects of the use of learning platforms in teachers' perceived motivation towards their educational activities, perceived usefulness, and perceived ease of use. From the online interview to some English teachers that have the willingness to confirm relate to their responses in the questionnaire as initial data, they declared that using Google Classroom, Quizizz, and WhatsApp in online teaching during Pandemic would be the most appropriate for them since not only they are familiar for the teacher and students but also those platforms are easy to use. They got prior knowledge 
about the application before the outbreak of the COVID-19 Pandemic came, especially LMS' Google Classroom'.

The second reason is the platforms are perceived usefulness; many features of LMS that have supported teaching and learning activity like stream, classwork, and grading. In the feature stream, you can announce given materials or topics that you want to discuss. In feature classwork, you can insert the task that the students have to do and achieve. In grading, you can know whether your students submit the task or not. Furthermore, this platform is integrated with a google form, google doc/slide that makes it the teachers easier to provide tests, whether multiple-choice or essay. Relate to WhatsApp, the teacher can use voice notes to give them the supervising of the task and explain more about the materials or topics. The teachers provide feedback for the students who are in the clue about the materials. Therefore, the process of teaching and learning would run smoothly.

The last reason is that platforms arouse students' motivation. The teacher said that using those platforms make the students more active in responding. Although they are not familiar with Google Classroom for the first time when time goes by, they learn a lot and be fast learners since they are millennial students that are ready and becoming fast learners in dealing with technology, especially platforms or applications in smartphones or computer. Since the collaboration or integration of those platforms, whether synchronous or asynchronous, the students are willing to ask dan try to complete the task completely. The features of chat or forum make the students feel free to ask to relate to the materials or even the task. Interesting activities provided in the platforms would encourage them to learn more, practice, and find answers or solutions.

\section{E. CONCLUSION}

From the discussion above, we can conclude that teachers choose certain platforms since it is easy to use whether for them or students themselves because it was simple and affordable, or in other words, it took low bandwidth. Besides, the platform they used is more popular or familiar to them, and the features are suitable for their materials. Since they used several learning platforms, they can combine one platform with another one as their learning goals. Another point, teachers should employ various interactive platforms to make students more engaged in class, whether in responding, collaborating, and interacting with the teacher and other students. Next, there should be training or workshop for teachers to learn and practice other learning platforms to explore more in providing practical and engaging activities. Furthermore, there is no exact or best platform to use in the interactive teaching and learning 
Lasmi, Wahab, Engaging Students with Some...

process. It depends on the teachers ` needs based on the material they should deliver, teachers` skills in using the technology, school policy and students`environment in this pandemic era.

\section{REFERENCES}

As, I. (2011). The 12 Key Benefits of Learning Platforms. London: University of London's Institute. Covey, S. R. (1990). The 7 Habits of Highly Effective People. New York: The Free Press.

Egbert, J. L., \& Shahrokni, S. A. (2019). Balancing Old and New: Integrating Competency-Based Learning into CALL Teacher Education. 15(1), 3-18.

Feldman, R., \& Zucker, D. (2002). Teaching and Learning Online - Communication, Community, and Assessment. Massachusetts: University of Massachusetts.

Garmire, E., \& Pearson, G. (2006). Tech Tally: Approaches to Assessing Technological Literacy. Washington D.C.: National Academies Press.

Gomez Ray, P. (2016). Measuring Teachers And Learners' Perceptions Of The Quality of Their Online Learning Experience. 146-163.

Huang, H. M., \& Liaw, S. S. (2005). Exploring Users' Attitudes and Intentions toward The Web as A Survey Tool. 21(5), 729-743.

Joshi, R., \& Kaur, G. (2011). Role of Internet in A Language Classroom. 1(4).

Muthi'ah, \& Galib, S. A. (2020). Students' Perception on the Use of Humor in English Teaching Process. $6(1)$.

Philp, J., \& Duchesne, S. (2016). Exploring engagement in tasks in the language classroom. 36, 50-72.

Ryan, S. (2001). Is Online Learning Right For You? 73(6), 54-58.

Schiler, J. (2003). Working with ICT: Perceptions of Australian Principals. 41(3), 171-185.

Susetyo Harjanto, A., \& Sumarni, S. (2019). Teachers' Experiences in the Use of Google Classroom. ELLiC Proceedings, 3, 172-178.

Yanti, H., Setiawan, A., Nurhabibah, \& Yannuar. (2018). Teacher's Perception about the Use of E-Learning/Edmodo in Educational Activities. Materials Science and Engineering. Presented at the IOP Con2nd International Conference on Innovation in Engineering and Vocational Education, Indonesia. doi: 10.1088/1757-899X/306/1/012055 